\title{
Editando o Livro de José de Arimateia'
}

Ivo Castro*

RESUMO: O Livro de José de Arimateia, cópia quinhentista de uma tradução portuguesa do romance arturiano francês Estoire del Saint Graal, ainda não dispõe de uma edição crítica. Este artigo propõe que tal edição tente reconstituir o original duocentista da tradução, para isso procedendo a emendas baseadas na tradição francesa, em vez de se limitar a reproduzir o texto português do século XVI. Como amostra do procedimento proposto, é editado o cap. $\mathrm{XCI}$, onde figuram algumas lições que sugerem que o ms. francês que serviu de original à tradução ocupava uma posição estemática muito elevada.

PALAVRAS-CHAVE: Crítica Textual; literatura francesa medieval; Santo Graal.

।

lguns dos mais importantes textos da literatura medieval portuguesa parecem ter o destino de serem editados tarde e devagar. Quando Carolina Michaëlis publicou em 1904 a sua edição do Cancioneiro da Ajuda, tinham decorrido vinte e sete anos sobre os meses em que, recém-chegada a Portugal, passara uma temporada em Lisboa para transcrever o códice e preparar a sua publicação, que chegou a estar anunciada como iminente. Quando Karl Pietsch iniciou em Chicago (1924-5) a publicação dos textos arturianos a que chamou Spanish Grail Fragments, tinham passado igualmente vinte e sete anos sobre a época em que transcrevera o ms.

* Universidade de Lisboa.

1 Este artigo baseia-se em dois textos publicados anteriormente: "Sobre a edição do Livro de José de Arimateid", Matéria de Bretanba em Portugal, ed. L. Curado Neves, M. Madureira, T. Amado, Lisboa, Colibri, 2002, p. 59-68 e "Josefes caminha sobre as ondas", eHumanista. Journal of Iberian Studies, vol. 8, 2007 (http://www.ehumanista.ucsb.edu/volumes/volume_08/ index.shtml). 
1877 da Biblioteca Universitária de Salamanca, então ainda depositado em Madrid, na Biblioteca de Palácio. Menos tempo decorreu entre a transcrição que o Pe. Augusto Magne concluiu em Viena da Demanda do Santo Graal, em 1925, e a publicação da sua primeira edição no Rio de Janeiro em 1944: apenas dezanove anos. Muito mais demoraria Joseph-Maria Piel a dar à luz a sua edição da Demanda: tendo transcrito o códice vienense cerca de 1927, por injunção do director da Imprensa da Universidade de Coimbra, Joaquim de Carvalho, que antes desafiara Magne, Piel viu a impressão do seu trabalho ser interrompida em 1934 por encerramento da editora e só viu a obra publicada em 1988, graças à colaboração de Irene Freire Nunes: sessenta anos de espera. Quase tanto- cinquenta anos - levou Lindley Cintra a acabar de publicar a sua edição da Crónica Geral de Espanba de 1344: fez a transcrição entre 1945 e 1950 e publicou o primeiro volume em Lisboa no ano seguinte, mas o quarto volume teria de esperar até 1995. Fanni Bogdanow, quando a conheci em 1972, já anunciava uma edição dos fragmentos franceses da Queste-Mort Artu, que só começaria a publicar vinte anos mais tarde.

Estas demoras fornecem o enquadramento ideal para o tempo longo da minha própria edição do Livro de José de Arimateia. Tendo iniciado o estudo do texto em 1971, com vista ao doutoramento, realizei a transcrição até 1974, tendo tomado como base uma colecção de fotografias do ms. 643 e a leitura diplomática de Henry Carter (1967), que se revelou utilíssimo auxiliar de uma decifração não-aventurosa das letras cursivas de chancelaria com que foi escrito. A minha transcrição foi dactilografada, em papel barato que amareleceu rapidamente e impossibilitou que, mais tarde, o texto fosse digitalizado através de leitura óptica. Ainda nesse período de 1971-74, fiz uma revisão integral da transcrição à frente do ms. da Torre do Tombo, o que permitiu resolver numerosas leituras conjecturais de Carter (as quais ele assinala com asterisco) e que são quase sempre devidas a manchas de tinta, ilegíveis em fotografia mas não no papel. Acabei este trabalho com a convicção de que uma edição interpretativa do códice único lisbonense não seria inteiramente satisfatória e que, se recorresse amplamente à tradição manuscrita francesa da Estoire del Saint Graal, poderia levar a cabo uma edição melhor (adiante direi o que entendo por isto); faltando então uma edição crítica da Estoire, que não cabia na minha competência realizar, ocupei-me de outras coisas. Na tese que apresentei em 1984, figura uma edição parcial do texto, que vai até ao cap. XLVI, precisamente no ponto em que termina o fragmento castelhano do ms. 1877 de Salamanca e a partir do qual deixa de ser possível contar com o seu testemunho para o estabelecimento do texto português (detecção de erros, lacunas e variantes); também incluí no aparato dessa edição parcial, com o objectivo de fundamentar a reconstituição de um estado do texto português mais antigo 
que o patente no ms. da Torre do Tombo, dados da colação com alguns mss. franceses da Estoire obtidos através de edições - o ms. British Library Royal 14.E.iii., editado por F. J. Furnivall (1861) e o ms. Le Mans 354, editado por Hucher (1874) - ou através de consulta directa - os mss. da British Library usados por Sommer (1909) ${ }^{2}$ e principalmente o ms. 2427 da biblioteca municipal de Rennes -, e ainda a edição princeps parisiense de 1516, feita por Jehan Petit, Galliot du Pré e Michel le Noir. Mas continuava a faltar uma edição crítica da Estoire, que várias notícias indicavam estar a caminho: recordo, por exemplo, a indicação dada por Roger Lathuillère de que valia a pena aguardar a conclusão de trabalhos que estariam em curso em Paris sobre a tradição manuscrita da Estoire, o que era com certeza uma alusão à actividade de JeanPaul Ponceau, que apresentou um doutoramento de 3..$^{\circ}$ ciclo em 1983 e um doutoramento de Estado em 1989 com teses que não conheço e que se viriam a materializar perante o público na sua edição de 1997.

Como é natural que, após a edição de Ponceau, os críticos se orientem para a apreciação e eventual revisão dos seus resultados mais do que para a produção de edições alternativas à sua, onde eventualmente pudesse encontrar materiais de interesse ainda não revelados, pareceu-me não haver motivos para esperar mais e comecei a pensar em publicar a edição do texto português, revisto com base não só nos materiais de que já dispunha, mas também nos mais recentes. Entre estes, convém destacar, por serem aqueles que se vieram adicionar ultimamente ao dispositivo crítico que já possuía, os dados da edição de Ponceau e também os dados divulgados em 1991 por Fanni Bogdanow na edição da Version Post-Vulgate, que interessam quase por igual a todos os romances que fazem parte do ciclo. Por essa altura, ou pouco depois, foi anunciado que Aida Fernanda Dias tinha identificado, em arquivo, um fragmento do José de Arimateia mais antigo que o lisbonense, o que prometia introduzir modificações interessantes no nosso conhecimento da tradição manuscrita. A publicação, prevista para 2003, só veio a concretizar-se em 2007; não desejando fugir ao ritmo a que estes assuntos estão habituados, reservo para mais tarde as minhas opiniões sobre o fragmento e sua interpretação.

Coincide, assim, este período com o reavivar dos estudos dedicados ao José de Arimateia. Estudos que também se reacendem em torno da Estoire, que, como nos recorda Michelle Szkilnik, sempre foi menosprezada pela crítica: "Jusqu'à très récemment, l'Estoire n'avait guère suscité l'enthousiasme des critiques" (1991, p. 1). Quando há mais de trinta anos me aproximei pela primei-

2 O ms. principal de Sommer é o BL Add. 10292 (sigla So), mas aquele que mais semelhanças tem com a tradição peninsular é o BL Royal 19.C.xii. (sigla A), cujas lições vêm no aparato. 
ra vez do manuscrito da Torre do Tombo, paleograficamente assustador e contendo um texto pouco prezado, talvez porque pouco lido, seria difícil imaginar que no presente tantas dissertações viriam a ser elaboradas a seu respeito e ao mesmo tempo. Desta verdadeira "pressa de gente" retiro com gratidão um claro incentivo para as muitas operações de revisão que ainda são necessárias ao apuro do texto que um dia virei a editar. Nunca o José de Arimateia deve ter sido tão lido e estudado como nos nossos dias. No colóquio Matéria de Bretanha em Portugal, que Leonor Curado Neves, Margarida Madureira e Teresa Amado organizaram em 2001 na Faculdade de Letras de Lisboa, foram apresentadas cinco comunicações que o citam no título, correspondendo algumas a dissertações em elaboração. Então, já fora defendida em São Paulo a tese de doutoramento de Sílvio Toledo Neto (2001), que estuda primorosamente a linguagem do ms. da Torre do Tombo nas suas várias camadas cronológicas.

Não creio que em algum momento do passado se tenha registado tanta leitura simultânea do texto. Seguramente tal não acontecia quando o comecei a estudar: suspeito até que o meu orientador Lindley Cintra, que com suave persistência me chamou ao medievismo, nunca tenha sido seu familiar. O Dr. Cintra queria que eu fizesse uma tese sobre a língua mista do José, a qual ele supunha dever apresentar leonesismos que comprovariam a tese de Pietsch e, durante algum tempo, de Bohigas Balaguer sobre uma tradução feita em Astorga do francês para uma língua que combinaria elementos do galegoportuguês e do leonês, e que constituiria, no plano da língua literária, o espelho da linguagem tabeliónica que o próprio Cintra estudara nos foros de Castelo Rodrigo e de outras povoações da região fronteiriça de Ribacoa. Afinal, como se viria a tornar patente, e não teria podido passar despercebido ao Dr. Cintra, o ms. da Torre do Tombo não apresentava leonesismos, nem marcas que sugerissem um antecedente leonês ou castelhano, mas sim formas linguísticas de um português muito arcaico, talvez pré-dionisíaco, já notadas por José Joaquim Nunes e por Rodrigues Lapa, e além disso revelava em passagens prolongadas uma grande fidelidade àquilo a que por facilidade chamamos o seu original francês, uma fidelidade tão grande que parece resultar de uma tradução feita palavra a palavra, em que não se vê como sobraria espaço entre a palavra francesa e a sua tradução portuguesa para que outra língua intermediária se imiscuísse. Refiro-me a paralelismos frequentíssimos como o que ressalta de passagens como esta: 


$$
\text { José (cap. IV, § 5) }
$$

$\mathrm{E}$, depois que isto dixe, veio ia voz assi como de bozina, e depois veio um som do ceo tam grande que me pareceo que o firmamento caía e que a terra se somia.

$\mathrm{E}$, se a claridade era ante grande, cento tanto foi maior então, assi que eu cuidei que o lume dos olhos perdera e caí em fu terra esmorecido.
Estoire, ed. Ponceau, $\S 7$

Et quant il ot che dit, si cria une vois autresi com une buisine.

Et quant ele ot crié, si vint uns si grans escrois de haut ke il me fu avis que tous li firmamens fust keüs et ke la terre fust fondue jusk'en abisme.

Et se la clartés eut esté grans devant, lors fu graindre a chent doubles, car j'en fui si esbahis ke bien en quidai avoir pierdu la veüe; et si caï a terre autresi comme pasmés.

Tudo isto apontava para uma tradução feita directamente do francês para o português, em data muito recuada. A identificação do tradutor Joam Vivas com uma personagem próxima da corte de Afonso III veio reforçar essa sugestão e abrir novas perspectivas: não se tratava apenas do José de Arimateia, mas também da Demanda, e em jogo não estavam apenas os textos em português, mas também os castelhanos, visto que Vivas se responsabilizava tanto pelo José português como pela Demanda castelhana. Mantinha-se a hipótese da origem comum das versões nas duas línguas, origem que vários autores, desde Lapa até Bogdanow, passando pelo Bohigas da segunda fase, consideravam ser portuguesa e que a cronologia - tendo em conta que a tradução teria sido feita em Portugal no tempo de Afonso III, a partir de textos redigidos em França, na região que ele habitara durante os últimos anos da sua estada aí - permitia rodear de uma encenação histórica invulgarmente colorida e detalhada. Longe ia a hipótese da língua mista leonesa, em que aliás deixei rapidamente de crer, quando observei que certas formas "ocidentais" dos textos editados por Pietsch não se encontravam no ms. de Salamanca, mas consistiam em formas genuinamente castelhanas que o editor leonizara, galeguizara ou aportuguesara, romanticamente convencido de que assim devolvia os textos à sua língua de origem. São eloquentes a este respeito tanto a introdução de Pietsch aos Spanish Grail Fragments, como a crítica de Bohigas ao "exagerado zelo" de Pietsch em encontrar formas galego-portuguesas no seu texto (Bohigas 1925, p. 88 e 94n; Castro 1988, p. 1123-1129).

Foi assim que não fiz a tese de linguística que o Dr. Cintra me encomendara. Mas é provável que, mesmo se a língua dos materiais fosse aquela que ele esperava, eu tivesse acabado por fazer a tese que fiz: uma tese de filologia, centrada na descrição do ms. da Torre do Tombo, na pesquisa das 
circunstâncias históricas que envolveram a sua produção em 1543 e a sua travessia do tempo, na conjecturação das origens remotas e mais próximas do texto, na evocação dos vários homens da sua vida (Joam Vivas, que o traduziu, Manuel Álvares, que o copiou para o seu corpo actual, Teotónio de Bragança, que o enclausurou na Cartuxa e assegurou que chegaria aos dias de hoje quase intacto, de papel virginal e lombada tão pouco aberta que nas dobras ainda se guardavam as areias que resolveram a datação da cópia, Mário Martins que beneditinamente, se me é permitida a confusão de ordens, o leu e copiou e, último e principal, Henry Carter, o autor da única edição completa publicada do texto). E teria feito uma tese de filologia porque, antes de estudar a língua do texto ou, se a inclinação para aí fosse, algum aspecto da sua construção estética, era preciso voltar a editar o texto. Era preciso produzir uma nova edição postCarter, que fosse legível sem que o esforço da leitura ocupasse o centro da actividade; que não se resignasse a ser uma edição interpretativa, pois, apesar de haver um único testemunho do texto português, esse não é um testemunho único, mas o último de uma linhagem talvez curta, constituída pela tradução original de Vivas e, pelo menos, por uma cópia intermédia que teria recebido o cólofon de Astorga, cópia que podemos identificar com o códice iluminado de quase duzentos anos, que o jovem Manuel Álvares adquiriu nos inícios do século XVI a uma velha de Riba d'Âncora. Existia, pois, o convite a que a edição não se limitasse a reparar as falhas evidentes do tecido linguístico, que não precisam de outra corroboração que o conhecimento da língua para serem detectadas e emendadas, mas que tentasse reconstituir o estado inicial do texto português.

Para fazer isso, era necessário considerar que a curta linhagem portuguesa do José de Arimateia mais não é que um ramo de tradição manuscrita mais ampla, de que também faz parte, nas proximidades, o texto fragmentário castelhano de Salamanca, com o estatuto de descendente do original de Vivas, ou de um intermediário. Essa tradição manuscrita mais ampla é, afinal, a da Estoire, com os seus sessenta manuscritos distribuídos pelas duas redacções longa e breve, alguns deles pertencendo a uma redacção híbrida que alterna entre as duas outras. Um deles é o ms. 2427 de Rennes, que Fanni Bogdanow considera o mais próximo dos textos peninsulares, o que o meu exame confirma em larga medida, não sem levantar certas dúvidas que só serão esclarecidas por uma comparação sistemática entre os dois mss., que Bogdanow, se a fez, não divulgou e cuja utilidade Carlos Pio deixou entrever na tese que fez sob minha orientação (2003). Este ms. de Rennes ganhou ainda maior notoriedade graças a Ponceau. Este, que na sua edição não publicada de 1989 tinha tomado por ms. de base o 354 da biblioteca municipal de Le Mans, ou seja o mesmo ms. que servira para a edição de Hucher, mudou de dispositivo na edição de 1997, passando a usar sucessivamente dois mss. de base: o texto do 
vol. I (§§ 1-444) foi estabelecido com base num ms. sem cota da Bibliotheca Philosophica Hermetica de Amsterdam, antes pertencente à colecção Phillips, n. ${ }^{\circ} 1045$, enquanto o vol. II ( $\left.\S \S 445-906\right)$ se baseia precisamente no ms. de Rennes. Devo confessar que isto me causa sentimentos mistos: por um lado, a importância que Bogdanow atribui ao ms. de Rennes é corroborada por um crítico que não parece morrer de amores pela tese da Post-Vulgata; por outro lado, a edição de Ponceau que tanto aguardei chama a atenção para um dos mss. que mais abundantemente eu já utilizara e, assim, dá respostas que já eram conhecidas.

Para editar o José de Arimateia português, como venho sugerindo, coloca-se a seguinte opção de método:

a) ou tomo como meta a atingir, mas a não ultrapassar, o estabelecimento do texto da Torre do Tombo, ou seja, a cópia mandada fazer por Manuel Álvares;

b) ou reconstituo o texto que saiu das mãos do tradutor peninsular até onde o permitirem os manuscritos disponíveis (incluindo, nos seus limites, o fragmento recém-revelado)."

Ambos os métodos se inscrevem no quadro da crítica textual neolachmanniana, diferindo apenas na medida em que o segundo recorre aos testemunhos geneticamente mais ligados ao ms. da Torre do Tombo (castelhanos e franceses) para identificar lugares que tenham sofrido corrupção durante a transmissão depois da tradução original, corrigindo-os ou assinalando a sua posição conforme os casos. Ilustro por um exemplo muito simples como se aplicam um e outro métodos.

No final do encontro de Vespasiano com Joseph (cap. XXVI, 1), uma voz acode a Joseph durante o sono e diz-lhe: "ora veyo que tu irás pregar e mostrar o meu nome..."

Isto, que não faz muito sentido, foi escrito pelo copista, que era o próprio Manuel Álvares, visto que nos encontramos no fl. $14 \mathrm{v}$ e portanto no primeiro caderno do códice, único que ele copiou. O defeito desta passagem não passou despercebido a Álvares, que a corrigiu, passando veyo para veJo; esta correcção é conjectural, sinal de que o exemplar que Álvares reproduzia já trazia o erro ou estava danificado, não se tratando, portanto, de uma lacuna ocorrida no acto de cópia. Mas trata-se de uma lacuna, provada tanto pelo texto castelhano (vien el tiempo en que) como pelo francês (est venuz, li termes que).

Por aqui se percebe que a tradução original portuguesa devia trazer "ora veyo o tempo que tu irás pregar...", tendo o segmento o tempo desaparecido a meio da transmissão, o que impediu Manuel Álvares de o utilizar para corrigir o problema. Perante isto, como proceder no quadro de uma edição 
interpretativa? Esta tem de se contentar com o estado em que Álvares deixou o texto, "ora vejo que tu irás pregar", que em seu favor tem ser uma lição da mão do responsável superior da confecção do códice e ser sintacticamente aceitável. Mas perde-se bastante, pois se trata de uma daquelas vozes cominatórias que regem a acção das figuras e, neste caso, precisamente, deveria anunciar a Joseph que chegou o momento oportuno de iniciar a sua grande missão evangelizadora. Em vez disso, temos banalmente uma voz que, debruçada à janela, vê. A edição reconstrutiva, em vez disto, ignorará a emenda de Álvares, preferirá a lição inicial veyo e preencherá a lacuna com a ajuda das versões nas outras línguas: "ora veyo [o tempo] que tu irás pregar...", o que parece muito mais satisfatório.

Mas não fica por aqui a reformulação da edição que tenho em mãos. Também no plano dos critérios de transcrição me afasto das anteriormente adoptadas "Normas de transcrição para textos medievais portugueses", do Boletim de Filologia (Castro, 1973), elaboradas sob a orientação de Luís F. Lindley Cintra com a intenção geral, que na época não parecia ingénua, de tornar os textos antigos mais acessíveis a um público numeroso, constituído por "leitores comuns". Por isso, a edição que fiz aproximava-se bastante da norma ortográfica moderna e previa formatações convencionais de texto (temese, quando imperfeito do conjuntivo, era vertido para temesse), sem pisar o risco da fidelidade grafemática ao sistema fonológico reconstituível para a época de escrita do manuscrito (meados do século XVI), inclusivamente introduzindo dispositivos gráficos ad-hoc, nem modernos nem quinhentistas, para sugerir ao leitor a articulação que a palavra teria tido na boca do escriba (a mesma grafia temese era, assim, transcrita como temê-se quando correspondia a um perfeito reflexo, na 3. ${ }^{a}$ pessoa do singular, assim se evitando a excessiva intervenção patente em teme[u]-se).

Até certo ponto, esta modernização tinha cobertura dada pela transcrição diplomática de Carter (1967), pois o campo bibliográfico ficava razoavelmente satisfeito com duas edições situadas nos extremos opostos do respeito pela estrutura linguística do texto; não excluo a possibilidade de no futuro vir a publicar uma edição normalizada com tais características. Mas o espaço que medeia entre elas é demasiado vasto e admite, como é minha convicção actual, produtos que conciliem virtudes de uma e de outra soluções extremas. Quem conheça imagens do cód. 643 sabe que a solução intermédia não será o facsimile, já que quase todas as escritas nele usadas são encadeadas de chancelaria, muito pouco penetráveis. Portanto, a solução deverá ser outra.

Como disse, a minha anterior transcrição neutralizava a variação ortográfica entre a letra dos numerosos copistas que se alternaram na confecção 
do manuscrito do José de Arimateia, cada um com sua identidade gráfica e com atitudes divergentes no que toca à conservação das lições do exemplar que usaram na cópia. Uma transcrição mais próxima e reveladora da compartimentação codicológica e paleográfica do manuscrito oferece, portanto, vários benefícios.

Por outro lado, a linearidade ininterrupta da transcrição de Carter, vinda do manuscrito, torna extraordinariamente difícil reconhecer a estrutura sintáctica e a alternância de discurso directo e indirecto. São, por isso, claros os benefícios de uma edição que revele essas estruturas por meio da pontuação, da abertura de parágrafos e de outros dispositivos. E que, no mesmo nível de intervenção, regularize o uso de maiúsculas e minúsculas e a unidade vocabular (embora tanto a justaposição de um vocábulo com os clíticos adjacentes, como a fragmentação de um vocábulo nas sílabas que o constituem, sejam práticas frequentes e individualizadoras de cada copista, que precisam de ser registadas em separado, mas não indispensavelmente dentro do texto).

Em outro aspecto é conveniente ir além de Carter. O seu apartado denominado "Paleographical notes" (p. 383-400) precisa de ser superado: constituem-no decifrações hipotéticas que no exame directo do manuscrito resultam claríssimas e se devem, porventura, à má qualidade das fotografias que utilizou; propost0as de interpretação de formas enigmáticas, ou nem isso; correcções que uma edição não-paleográfica facilmente incorpora no texto crítico; finalmente, descrições de acidentes de escrita (cancelamentos, lacunas, entrelinhas, etc.), únicas com real interesse.

Ponderados todos estes dados, inclino-me hoje para uma edição conservadora, que não perca de vista que há leitores a servir, mas os identifique como leitores exigentes e que não gostam de ser tratados com condescendência. No campo bibliográfico, haverá ainda espaço, e então de modo mais justificado, para uma edição normalizada.

A penosa tarefa de reconverter a grafia do texto, devolvendo-a a um ponto mais aproximado das várias grafias individuais do manuscrito, está entregue a Sílvio Toledo Neto, com quem mantenho um diálogo rico e praticamente ininterrupto desde que nos encontrámos na discussão da sua dissertação de doutoramento. Além disso, ele procedeu a mais uma revisão da minha leitura, apoiado em novas fotografias, a qual permitiu eliminar algumas dezenas de maus passos por mim dados. 
Para exemplificar o que acabo de expor, vou publicar como amostra tanto dos critérios de transcrição, como das oportunidades de emenda textual oferecidas pelas diversas fontes disponíveis - o episódio da travessia milagrosa do canal da Mancha pelos cristãos da companhia de Josefes, que caminhou sobre as águas transportando-os na aba da sua camisa (todo o cap. XCI, fols. $211 v-215 v$ ). São adoptadas as seguintes principais convenções:

a) são conservadas por princípio as características da escrita do texto;

b) são introduzidas as seguintes alterações sistemáticas:

1. criados períodos e parágrafos, de acordo com uma interpretação da estrutura da sintaxe e do discurso; identificadas as tiradas de discurso directo por parágrafo iniciado por travessão (ocasionalmente, no interior de parágrafo, por aspas);

2. dividido o texto em cláusulas numeradas;

3. introduzida pontuação;

4. regularizado o vocábulo gráfico, através da ligação e separação de segmentos; do uso de hífen e apóstrofe; e da distribuição de maiúsculas e minúsculas;

5. reservados os grafemas $<_{\mathrm{v}}>$ e $<\mathrm{j}>$ para valores consonânticos e os grafemas $<\mathrm{u}>$ e $<\mathrm{i}>$ para valores vocálicos ou semivocálicos;

6. desenvolvidas as abreviaturas por meio de itálico, com excepção de algumas formas muito frequentes, em que a extensão do desenvolvimento não é marcada: que, Deos, Senhor, Jesu Cristo, etc.;

7. introduzida acentuação apenas para prevenir ambiguidade homográfica (chegárão), se o contexto não bastar para identificar as categorias morfológicas pertinentes.

c) as intervenções editoriais (emendas ou conjecturas) são contidas entre colchetes.

d) o aparato tanto descreve particularidades do suporte e da escrita, como dá a colação dos testemunhos e ainda outras anotações textuais; as notas remetem para as cláusulas em que o texto foi dividido.

No estabelecimento do texto, foram usados os seguintes testemunhos:

L 212r-215v Lisboa, IAN/TT, Livraria, cód. 643

R 69a-70 a Rennes, Bibl. Municipale, 2427

P 88d-89d L'Hystoire du Sainct Greaal, Paris, 1516, ofic. de Jehan Petit, Galliot du Pré e Michel le Noir 
So. $\quad$ 209-212 Sommer (o ms. base é Londres, BL Add. 10292)

A Londres, BL. Royal 19.C.xii (ms. secundário de Sommer)

Pon. 649-658 Ponceau (R é o ms. base do vol. II)

\section{Capitolo XCl \\ Do que acomteçeo a Josep e a seu filho Josefes depois que se partirã de Sarrat e como pasarã o mar sẽ barca}

${ }^{1}$ Diz a estoria que, quoamdo Josefes se partio com sua companhya e seu padre da çidade de Sarrat, hamdáraom tamto que pasárão o rio de Eu-[212r] frates e outras muitas terras. E achárão muytas [gentes que], porque herão christãos, travárão neles, mas numca forão em lugar presos que os Noso Sennhor nom lyvrase. ${ }^{2}$ Hũua noute, no ymverno, jazião em hum mato em collchas que fizerão. E comêrão muy bem aquela noute e jazia Josepe com sua molher, boa dona a Deos e ao mumdo. E muyto amavã e a louvavão quoamtos a conheçião. ${ }^{3} \mathrm{E}$, eles asym jazemdo, dise hũua boz a Josepe:

- Mãda-te dezer o Gram Mestre, por cujo mãdado vieste a esta terra, que jazerás esta noyte com tua molher, asym como omem cõ molher deve jazer, que ele quer que ajas sememte per que a terra que te tem prometida seja guoardada e mamtida. E ho que sayr sera filho e por-lheas nome Galaz. Ysto te mamda ho ordenador de todas as cousas.

${ }^{4}$ A ysto respomdeo Josep:

- Vedes haquuy o servo de Jhesu Christo, aparelhado pera fazer suua vomtade. Mas eu são ja taão velho e fraquuo e camsado que nom sey como ysto posa fazer.

- Nom te maravylhes, dise a voz, porque asỹ a-de ser.

${ }^{5}$ Emtão se calou. E Josep aquela noute jouve com suua molher e ouve hum filho que se chamou Galaz, que depois foy tão bom omem e tão bom cavaleiro d'armas [212v] que bem devemos falar em seus feitos ãte os alltos omẽs e amte outros, pera que os maos se sofrão de seuus maos feitos e malldades e os bos, que tẽ hordem de cavalaria, se cõrregão e se mamtenhaão bem com Deos. ${ }^{6}$ Depois que ysto dise a voz a Josep, ele e Josefes he toda suua companhia hyaão cada dia diamte o Samto 
Vazo, amte que comesem, fazer suuas oraçoes que Noso Senhor hos levase a terra que lhe prometera. Tamto amdárão asym ate que chegáraão ao mar. E esto foy a hum sabado hao serão.

${ }^{7} \mathrm{E}$, quoamdo hy chegárão, nem hachárão nao nem outra barqua allgia ẽ que da houtra parte pudesem pasar. E forão muy trystes, que teverão duvida de ficarem ali domde estavão. E começárão de chorar e pidir a Noso Sennhor merçe, que lhes acorrese àquela trysteza, que numca taão myster lhes fora suua ajuda des que saírão de suuas terras; ${ }^{8}$ ẽtaão forão ha Josefes, seu bispo, e choramdo lhe diseraão:

- Senhor, que faremos pera pasáremos, que no mar nom ha nao nem gale que da outra parte nos pase? Por Deos, dezede-nos se pasaremos ou se fi-[213r]caremos, ou se he esta a terra que nos Deos prometeo a nos e a nosos yrdeiros, aquela omde avemos de acabar nosas vidas em serviço de Noso Sennhor.

9 Quoamdo Josefes ysto ouvyo, teve em seu coração gram dor, porque herão fora de suuas terras e leixárão suas riquezas, e mais o mais deles herão seuus paremtes; $1 / 2$ tão dise:

- Amigos e boas donas, nõ vos descomfortedes muyto ata que nõ vejades por que. Eu vos diguo que aquele que nos aquuy trouxe nos levará alem, se sua võtade for de la ýremos. ${ }^{10}$ Mas eu vos digo que nõ vos levará todos la e dir-vos-hey por quue. Quoamdo vos partistes de vosas terras e leixastes o viço do mumdo por servirdes Jhesu Christo, vos lhe prometestes que ho servyriades como filhos devem servyr a padre. ${ }^{11}$ Tamto quer ysto dezer como quue vos guoardariades dali adiamte de pecar, como quer que hate li tinhês feito. E ele vos prometeo que vos daria quoamto vosos coraçoes soubesem cuydar e que vos livraria de quoamtos vos quizesem mall fazer. ${ }^{12} \mathrm{E}$ o que ele vos prometeo o teve muy bem, que numca depois lhe pidistes cousa que vos ele nom dese. E muytas vezes de muitos primçipes da terra fostes presos e ele vos livrou. ${ }^{13}$ Asym vos teve ele [213v] suua promesa, mas vós tivestes muy mall o que lhe prometestes, porque [à] amtrada da Momtanha das Atalayas, quoamdo ele comvosquuo falou, cada hum de vos lhe prometeo castidade e quue todos vos teriês limpamemte ate que vos ele mamdase que chegaseis a vosas molheres. ${ }^{14}$ Esta promesa lhe fizestes vós e sabede-lo muy bem. Ora houlhay como a compristes, que os mais de vos caystes ẽ luxuria ma e lixosa e os outros sam ja fryos de fazer bem. Mas o[s] que verdadeiramemte sempre tiverão suuas vomtades e seus coraçoes ẽ Jhesu 
Christo e sam aymda quemtes e feruemtes do foguuo do Esprito Sãto e da quemtura da caridade, as ỹ como herão no começo, e que guoardárão seuus corpos limpamemte e tiverão castidade como prometêrão, estes pasarão sem barquua e sem nao. ${ }^{15} \mathrm{E}$ o mar hos sofrerá, porque nõ ha neles peso de pecado nem de malldade. Estes pasarão porque suua fee os pasará alem, e ha gram limpeza que tiverão. E os que asỹ se nõ guoardárão e vivêrão em pecado, averão naos e gales e segir-nos-hão. ${ }^{16}$ E sabedes por que Noso Senhor quer que vos nõ apartedes [214r] de nós? É porque em nenhũua maneira ele quuer a morte do pecador, mas quer que viva, pera quue venha à carreira da verdade. Esto vos ei dito pera conheçerdes voso pecado e, quoamdo quer que for manyfesto este erro que fizestes comtra voso Deos, nom vos dezespereis, pois que amtes o fizestes.

${ }^{17}$ Quoamdo aqueles que se semtião cullpados naqueles herros de que os acusava Josefes ysto ouvíraão, fizeram-se afora e começárao hum taão gramde pramto que numca ho omem vyo mayor, e chamavam-se cativos mallhavẽturados. E seryam quoatroçemtos e sasemta. ${ }^{18} \mathrm{E}$ os outros, que nom herão ẽ esta cullpa, chegárão-se a Josefes e fimcárão os joelhos diamte dele e diserão:

- Senhor, como pode ser que nós pasemos?

Ele lhe dise:

- Ysto mereçedes vós muy çedo.

${ }^{19}$ E estes seriaão çemto e çimquoemta por todos, e herão os parẽmtes de Josefes.

Aquela noute hera mamsa e crara, e o mar mamso e chaão e sem tempestade, e a lua muy clara, e fazia muy bom tempo. Ysto hera em Abryll, him sabado, hum dia amte da resurreição de Jhesu Christo, que era bespora de Pascoa. E Josefes v[e]yo a seu padre e beijoou e dise-lhe:

- Padre, segide-me.

${ }^{20} \mathrm{E}$ despois beijou os houtros todos que a cabo dele estavão hum a hum e dise-lhes como dezia a seu padre. [214v] E foy pera emtrar no mar, mas hũua voz lhe dise:

- Josefes, nom emtres! Nom emtres hy asim, mas mete os que guoardã o vaso e depois despe a tua camiza e dize a teu padre que ponha os peis sobre a aba dela. ${ }^{21} \mathrm{E}$ despois chama os outros que beijaste e fação asym. E, se eles tiverão o que prometêrão ao Sallvador, poderão estar sobre a aba da camiza e bem os tera todos. Mas aqueles que nõ 
guoardárão sua promesa não poderão nela estar e a estes lhes serão necesarias naos e gales. E vós pasaredes este mar amte que seja dia.

${ }^{22}$ As ỹ como a voz mãmdou asỹ o fez Josefes, que ele chamou os que guoardavão o Samto Vazo e fez-lhes emtrar no mar e dise-lhes:

- Yde seguros, que ha vertude daqueste priçioso vazo vos guoardará e giará.

${ }^{23}$ E eles se metêrão loguuo no mar sẽ pavor e sem duvida e começárão yr por syma dele, asym como se fora terra cham. E levárão comsyguuo ho samto vazo que chamão o Samto Gryall. Quoãdo Josefes vyo que [eles] ja ẽ tall maneira tomárão seu caminho, espio a sua camiza e vistio outros panos e dise a seu padre que pusese os peis sobre a aba daquela camiza. ${ }^{24}$ E Josefes estava ja sobre ho mar [215r] e estemdera a camiza sobre a aguoa asym como sobre a terra. E seu padre se pos sobre a camiza. E chamou hum seu paremte quue avya nome $\operatorname{Br}[0$ ] ], que era casado com hũua suua filha, de que tinha doze filhos gramdes e fremosos, e metê-se demtro na camiza como Josepe fizera. ${ }^{25}$ Depois chamou Josefes todos hos outrõs çemto e çimquoẽta, huus depos hos outros e fe-los ẽtrar hum e hum n'aba da camiza. E a camiza se estemdeo por o prazer de Deos, que todos os hy acolheo afora sos doius, que não herão taes como devyão. E hum era padre do outro, e o pay se chamava Symion e o filho Mois. ${ }^{26}$ Quoamdo aqueles dous quyzerão emtrar na aba, ligeiramemte forão ao fumdo as ̃̃ como pedaços de chumbo. E Josefes, que bem nos conheçia, quoamdo os vyo asym afumdar, dise:

- Mall fizestes, que [v]os asym emganastes. Bem pareçe quoamta fe em vos ha.

${ }^{27} \mathrm{E}$ os que se forão ao fumdo com pavor da morte nadárão ate terra. E os outros que ficárão os forão hajudar a tirar.

Josefes, que diamte hya, começou de tirar por as mamgas da camiza por syma da aguoa e eles se ẽcomemdárão todos a Noso Senhor e me[215v] têrão sua esperamça nele. E acomteçề-lhes asỹ que, amte que fose dia, forão na Gram Bretanha e virão que a terra hera toda povoada de paganos.

Variantes, emendas e comentários

$\S 1$ L E achárão muytas, porque herão christãos, travárão neles | Pon. $648 \mathrm{Si}$ troverent plusors genz qui les aresterent et les voloient retenir, 
pot ce que crestien estoient | So. $208 \mathrm{Si}$ trouerent maintes gens qui les arresterent et les uaudrent retenir pour ce que crestien estoient Óbvia lacuna de L, que os testemunhos franceses permitem colmatar.

\$3 L cou $<$ s $>$ sas

Letra riscada por copista ou revisor.

\$5 L que tẽ hordem de cavalaria | P88d qui ayment cheualerie | R69a(Pon. 649) qui aient l'ordre de chevalerie | So. 209 qui tienent lordre de cheualerie

Lição singular de P. Esperar-se-ia que isto acontecesse mais vezes, mas um dos pontos interessantes deste exercício é verificar como uma edição parisiense do séc. XVI, tardia, costuma coincidir com uma tradução portuguesa contra secções da tradição ms. francesa. Este é um exemplo raro, que talvez se explique por meio de R: aient $>$ aiment.

§5 L mãos passim

Suprimiu-se o til de todas as ocorrências desta palavra devido à homografia com o substantivo feminino mão.

§5 L se mamtenhaão bem com Deos | P88d vers dieu et le siecle. | $\mathrm{R}($ Pon. 649) vers deu et vers le siecle.| So. 209 enuers dieu \& enuers le siecle.

Lição singular de L. A omissão de siecle (mundo) poderá não ser inocente.

\$6 L ele e $<$ so $>$ Josefes

Uma sílaba foi riscada antes de Josefes.

$\S 7 \quad$ L não passim

Suprimiu-se o til de todas as ocorrências desta palavra devido à homografia com o advérbio de negação não.

§7 L que numca taão myster lhes fora suua ajuda | P88d car a present en estoyt plus grant mestier $\mid$ R69b car il en estoit ore le greignor besoig (Pon.651 emenda para car il en avoient) | A(So.209) car il en auoient ore greignor mestier

Coincidência típica LPR (fora myster / estoyt mestier) contra o resto da tradição (auoient mestier). Ponceau, atraído pela lição mais comum, emenda R e oculta o facto relevante. 
$\S 8 \quad$ L pasáremos

$\S 9 \quad$ L ýremos

Não confundir com o futuro do indicativo; trata-se do infinitivo pessoal, com a particularidade de conservar a vogal postónica da penúltima sílaba, que depois desapareceria por síncope (Nunes: 1975, p. 302; Williams, 1974, p. 164, 2; Piel, 1945, p. 44-45): passáremos > passarmos, iremos > irmos. Segundo esta explicação, estaríamos perante formas verbais arcaicas, porventura representativas do estado linguístico da tradução do século XIII. No entanto, Clarinda Maia (1986, p. 757-778) regista formas deste tipo em documentos galegos medievais, mas não nos seus contemporâneos portugueses; regista-as também, em Portugal, em textos da segunda metade do séc. XVI (Pantaleão de Aveiro e no ms. Lorvão 32 da Regra de S. Bento), ou seja, quase contemporâneos do ms. de Lisboa do José de Arimateia. E, sem tomar partido, avança uma segunda explicação, paragógica, para a vogal postónica. Ficamos assim perante um dilema: ou se trata de um arcaísmo da tradução original, que escapou às cópias subsequentes, ou de uma novidade introduzida pelos copistas renascentistas.

$\S 9 \quad \mathrm{~L}$ ata que nõ vejades por que. Eu vos diguo |P89a sans scauoir pourquoy. ie vous dy | R(Pon. 652) devant que vos sachiez por coi. Je vos di | So. 209 deuant che que vous saues le porcoi. Ie uous di Na minha transcrição inicial, tinha: "ata que nom vejades, porque eu vos digo...". Mas todos os testemunhos franceses mostram, com pontuação explícita, que a sintaxe é outra e com isso me conformo. A rendição de savoir por ver tem interesse para a tradução portuguesa.

$$
\text { L soubesem cuydar | P89a = R(Pon. 652), A(So) penseroyent | So. }
$$
demanderoit

O acordo LPR (cuidar / penser) conta aqui com a participação do ms. secundário de Sommer, A. | A(So) sa promesse | So. 210: vos promesses

Note-se a concordância de LPA, mas não de R.

L porque amtrada da Momtanha das Atalayas | Pon.652, So. 210 a lentree del bois des Agaiz

A lacuna de L, falta da preposição, pode ter sido causada pela vogal inicial da palavra seguinte. 
$\$ 14 \quad$ L Mas o que verdadeiramemte

Uma mancha, que pode ser lida como $s$, foi inserida entre $o$ e que.

$\S 14$ L asỹ como herão no começo | $\mathrm{P}$ tem redacção diferente | R69c(Pon.653) come il estoient acostume. | So.210 com sil eussent fet acostumeement $\mid \mathrm{A}(\mathrm{So})$ come il estoient al comencement (assim também alguns testemunhos cits. por Ponceau.: BL Add 32125 (B para Sommer), Le Mans 354, BN 770)

$\S 17$ L quoatroçemtos e sasemta | P89b quatre vingtz ou soixante | Pon. 654 qatre cenz et soisante | So. 210 IIIJ. ${ }^{\mathrm{C}}$ \& lx.

§18 L Ysto mereçedes vós muy çedo | P89b et il leur dist que ce verroyent ilz prochainement $(\mathrm{R}$ concorda) $\mid \mathrm{A}(\mathrm{So})$ \& cil respont que ce sauront il prochienement

Aparentemente, lição privativa de L.

$\$ 19 \quad$ L Josefes vyo a seu padre e beijoou | P89b Et iosephus vint a son pere et le baisa | R69e(Pon. 655) vient a son pere, si le baise | So. uint a son pere si le baise

Bom exemplo de como o texto de L pode ser melhorado com segurança: todos os testemunhos recomendam a emenda vyo $>v[e] y o$. Além disso, todos confirmam que na complicada grafia beijoou se oculta o pronome pessoal átono: beijou-o. É característico do ms. L este clítico ser absorvido pelo ditongo antecedente, na $3{ }^{a}$ p. singular do pretérito perfeito, tanto grafica como fonicamente. Uma edição com as características desta aceita a emenda de vyo, mas não o desenvolvimento de beijoou, que terá de ser explicado em separado.

$\$ 20$ L: mete os que guoardã | P89b: metz deuant toy (R concorda) | So. 211 : met deuant cels qui

Ligeira lacuna de L, que ficará assim.

\$23 L vyo que hera Ja ẽ tall maneira tomarão seu caminho | P89c vid quilz estoyent ainsi encheminez| R(Pon.656) vit qu'il s'estoient si acheminez en tel maniere | So.211 uoit quil sont achemine en tel maniere

Não poderá ficar assim a lição de L, dificilmente compreensível. Basta emendar hera $>$ eles, para a frase ficar conforme com a tradição. 

para Bron.

Ponceau (II, 624) comenta a passagem nos seguintes termos: "tous les mss de la version longue (à l'exception du ms. BN 1427, fol. 189r, qui remanie le texte courant et qui porte Bron), ainsi que ceux de la vers. courte, portent ici Dro, ou Dron, personnage dont il n'est plus question dans la suite du roman. C'est probablement une erreur qui remonte à l'archétype de tous nos mss, car il s'agit vraisemblablement de Bron, qui est ici présenté pour la première fois au lecteur et qui réapparait ensuite au début du $\$ 766$ comme un personnage connu, et au début du $\$ 772$, où il précise lui-même qu'il a 12 fils." Sendo assim, Ponceau corrige para Bron o que, pelos vistos, era um erro unânime de todos os mss. franceses, incluindo Rennes, sua fonte principal. Tudo isto dá relevo à lição de L, que se mostra muito mais próxima de Bron: neste passo, em que o nome aparece pela primeira vez, apresentado como genro de José de Arimateia, é Bru, mas a partir do fol. 262r é Brou, onde se reconhece sem qualquer dificuldade a lição correcta. É lícito, pois, emendar o texto português, em todos os lugares, para Bron. E é oportuno perguntar como terá o original francês da tradução peninsular obtido a sua lição, mais perfeita que a do "arquétipo" admitido por Ponceau.

$\$ 25 \quad$ L hum era padre do outro e o pay se chamava Symion e o filho Mois | P89c: le pere fut nomme symeu et le filz moye | R69f (Pon.657) fu li peres apelez Symeu, et li filz Moys

Ao contrário de LPR, muitos mss. omitem o nome de Mois neste passo, mencionando apenas o pai. O banho forçado não é a única punição de Mois (ou Moisés). Mais tarde (caps. CIII-CIV), tenta ocupar o assento vago da Távola Redonda, a "silha perigosa" que estava reservada para Galaz, e é severamente castigado por isso. Sete mãos de fogo arrastam-no para um lugar de cativeiro, onde ficará muitas gerações. O pai, Symion, também passa por dificuldades. O parentesco entre ambos tem interesse crítico. A Queste Vulgata não sabe que Mois é filho de Symion, mas a Queste Post-Vulgata sabe-o e fala de uns cavaleiros que "andarom tanto que chegarom a ia abadia u jazia Simeu, o padre de Mois, no fogo na claustra da capela u jouvera ja naquela coita des tempo de Joseph Abaramathia atee entom assi como a estoria o ha ja devisado" (Demanda Piel-Nunes, cap. CCCLXIV). Daqui extrai Bogdanow a seguinte conclusão: "the fact that the Estoire and the Post-Vulgate Queste both make Moïs the son of Simeu is thus proof that the Post-Vulgate Queste knew and exploited the Estoire independently" (Bogdanow, 1966, p. 161). 
Não só: o facto de LR e P conhecerem o parentesco, mas os outros mss. da Estoire não, sugere a possibilidade de se estabelecer distinção, dentro da tradição da Estoire, entre testemunhos mais ou menos chegados à Post-Vulgata.

\$26 L Mall fizestes, que vos asym emganastes. Bem pareçe quoamta fe em vos ha. | P89c Vous fistes mal pour ce que nous cuydez decepuoir. Or appert bient vostre follie. | R(Pon. 657) Mal faisiez qui nos alez decevant! Ore apert il bien combien de foi il a en vos! (So. coincide com $\mathrm{R}$ )

Segundo os testemunhos franceses, Josefes não acusa Symion e Mois de se enganarem a si mesmos, como está em L, mas de tentarem enganar os seus companheiros de viagem. Por isso foram impedidos de subir para a aba da camisa. Impõe-se, portanto, a emenda vos $>$ nos.

\$27 L com pavor da morte danarão digo nadarão ate terra

Autocorrecção do copista de L.

\$27 L a terra hera toda povoada de paganos. | P89d, R70a(Pon. 658), So. 212 peuple de sarrazins et de payens.

A omissão da referência a sarražins, que todos os mss. franceses trazem, será uma lição privativa de $\mathrm{L}$, ou da tradução peninsular?

\section{Bibliografia}

BOGDANOW, F. (1966) The romance of the Grail. New York: Manchester University Press.

. (1991-2001) La version Post-Vulgate de la Queste del Saint Graal et de la Mort Artu, troisième partie du Roman du Graal. Paris: Société des Anciens Textes Français.

BOHIGAS, P. (1925) Los textos españoles y gallego-portugueses de la Demanda del Santo Grial. Madrid.

CARTER, H. H. (1967) The Portuguese book of Joseph of Arimathea. Paleographical Edition. Chapel Hill: University of North Carolina Press.

CASTRO, I. (1973) Normas de transcrição para textos medievais portugueses, em col. com Maria Helena Lopes de Castro, Isabel Vilares Cepeda e Virgílio Madureira. Boletim de Filologia, XXII, p. 417-425.

. (1984) Livro de José de Arimateia (Estudo e Edição do COD. ANTT 643). Lisboa. Dissertação (Doutorado), Universidade de Lisboa.

. Karl Pietsch e a sua edição dos Spanish Grail Fragments. Actas del I Congreso Internacional de Historia de la Lengua Española, II. Madrid: Arco-Libros. p. 1123-1129.

. (2002) Sobre a edição do Livro de José de Arimateia. In: NEVES, L. C.; MADUREIRA, M.; AMADO, T. (ed.) Matéria de Bretanha em Portugal, ed. T. Amado. Lisboa: Colibri. p. 59-68. 
DIAS, A. F. (2003-2006) A Matéria da Bretanha em Portugal: relevância de um fragmento pergamináceo. Revista Portuguesa de Filologia (Miscelânea Herculano de Carvalho, v. XXV, t. I, p. 145-221.

FURNIVALL, F. J. (1861-63) The history of the Holy Grail. London.

HUCHER, E. (1874-78) Le Saint-Graal ou le Joseph d'Arimathie. Le Mans.

MAIA, C. de A. (1986) História do galego-português. Coimbra: INIC.

NUNES, J. J. (1975) Compêndio de gramática bistórica portuguesa. Lisboa: Clássica.

PIEL, J.-M. (1945) A flexão verbal do português. Coimbra, sep. de Biblos, XX.

; NUNES, I. F. (1988) Demanda do Santo Graal. Lisboa: IN-CM.

PIO, C. (2003) O lugar do Livro de José de Arimateia na tradição da Estoire del Saint Graal. Lisboa. Dissertação (Mestrado), Universidade de Lisboa.

PONCEAU, J.-P. (1997) L'Estoire del Saint Graal, 2 vols. Paris : Champion.

SZKILNIK, M. (1991) L'archipel du Graal. Étude de l'Estoire del Saint Graal. Genève : Droz. SOMMER, H. O. (1909) The Vulgate Version of the Arthurian Romances, vol. I. Washington: Carnegie (repr. New York, AMS Press, 1969).

TOLEDO NETO, S. de A. (2001) Livro de José de Arimateia (Lisboa, AN/TT, Livraria, Cód. 643). Camadas lingüísticas da tradução ibérica ao traslado quinhentista. São Paulo. Dissertação (Doutorado) "Faculdade de Filosofia, Letras e Ciências Humanas, Universidade de São Paulo.

WILLIAMS, E. B. (1973) Do latim ao português. 2.ed. Rio de Janeiro: Tempo Brasileiro; Brasília: INL.

ABSTRACT: The Portuguese text Livro de José de Arimateia is a XVIth. century copy of an older translation of the French arthurian romance Estoire del Saint Graal. No critical edition has yet been published of the Livro. This paper proposes that such an edition should try to reconstruct the XIIIth. century original of the port. translation by means of emendations based on French manuscripts instead of just reproducing the extant port. copy. As a sample, chapt. XCI is edited here. Some of its readings suggest that the manuscript translated into Portuguese occupied a higher stemmatic level than most of the extant French manuscripts.

KEYWORDS: Textual criticism; medieval French literature; Saint Graal. 